\title{
Seasonal affective disorder and non-seasonal affective disorders: results from the NESDA study
}

Wim H. Winthorst, Annelieke M. Roest, Elisabeth H. Bos, Ybe Meesters, Brenda W.J.H. Penninx, Willem A. Nolen and Peter de Jonge

\section{Background}

Seasonal affective disorder (SAD) is considered to be a subtype of depression.

\section{Aims}

To compare the clinical picture of SAD to non-seasonal affective disorders (non-SADs).

\section{Method}

Diagnoses according to the Diagnostic and Statistical Manual of Mental Disorders (DSM-IV) were established in 2185 participants of the Netherlands Study of Depression and Anxiety. The Seasonal Pattern Assessment Questionnaire was administered to diagnose SAD. Symptoms of depression and anxiety were measured with the Inventory of Depressive Symptoms, the Beck Anxiety Inventory and the Fear Questionnaire.

\section{Results}

Participants with SAD, participants with a lifetime bipolar disorder and participants with a lifetime comorbid anxiety and depressive disorder scored highest in terms of psychopathology in the past year. The seasonal distribution of major depressive episodes was not different for participants with or without SAD.

\section{Conclusions}

SAD may be a measure of severity of depression with a subjectively perceived worsening of symptoms in the winter months.

\section{Declaration of interest}

Y.M. has received research funding and served as a consultant for Royal Philips Electronics NV and The Litebook Company Ltd. W.A.N. has received grants from the Netherlands Organization for Health Research and Development, the European Union, the Stanley Medical Research Institute, Astra Zeneca, Eli Lilly, GlaxoSmithKline and Wyeth; has received honoraria/speaker's fees from Astra Zeneca, Pfizer, Servier and Wyeth; and has served in advisory boards for Astra Zeneca, Pfizer and Servier.

\section{Copyright and usage}

(c) The Royal College of Psychiatrists 2017. This is an open access article distributed under the terms of the Creative Commons Non-Commercial, No Derivatives (CC BY-NC-ND) license.
Depressive disorders have a great impact on well-being and daily functioning and are a major health problem with a 12-month prevalence rate between 6.3 and $10.3 \%$ across Western societies. ${ }^{1,2}$ Diverging treatment results, partly ascribed to the non-specificity of major depression, have led to proposals for depressive subtyping models based on characteristics like observed symptom profiles, aetiology, time of onset, gender, duration of complaints and treatment response. ${ }^{2}$ Ideally, subtypes should represent homogeneous groups of cases and represent different underlying pathophysiological processes that allow us to develop specific treatment strategies.

Seasonal affective disorder (SAD) is one of the proposed subtypes of depression with a specific treatment strategy. ${ }^{3} \mathrm{SAD}$ is a syndrome originally defined to describe recurrent depressive episodes with a characteristic temporal pattern. The depressive episodes usually occur in autumn and winter and remit the following spring or summer. In the Diagnostic and Statistical Manual of Mental Disorders (DSM-IV and DSM-5), seasonality is added as one of the specifiers of bipolar or recurrent major depressive disorders (MDDs). According to this specifier, seasonal episodes should substantially outnumber non-seasonal episodes. Subsyndromal SAD (sub-SAD) is a milder form of SAD describing complaints in wintertime in participants who fail to meet the number of complaints required for a DSM diagnosis of depression. Sub-SAD can be considered to be part of a continuum of seasonality between no complaints at all and clinically depressed. Disturbance of circadian rhythm because of lack of daytime light in the winter months is thought to play a role in the aetiology of SAD. Light therapy is an efficacious and well-tolerated treatment for SAD with effect sizes equivalent to those of most antidepressants and has been adopted as the treatment of choice for SAD in treatment guidelines for depression. ${ }^{3,4}$
Yet, there still remains a debate as to whether SAD is a distinct depressive subtype or a pronounced seasonality trait of patients with fluctuating minor and major depression. ${ }^{5}$ Several researchers have questioned the validity of the concept of SAD. For example, Traffanstedt et al who could not find a relation between depression and season in a large population-based study, and Hansen who argued that disturbance in circadian rhythm seems to be more related to midwinter insomnia and tiredness during the day than to depressed mood. ${ }^{6-8}$ On the contrary, researchers stress the importance of longitudinal research and the low prevalence of SAD in population-based studies. ${ }^{9}$

In the Netherlands, Mersch et al ${ }^{10}$ studied the prevalence and characteristics of SAD and sub-SAD in the general population. In that study Mersch et al used the Seasonal Pattern Assessment Questionnaire (SPAQ), which is a commonly used screening instrument for SAD. ${ }^{11-13} \mathrm{SAD}$ and sub-SAD criteria were met by 3.1 and $8.5 \%$ of the respondents, respectively. However, no data are available yet on the prevalence of SAD in the Netherlands in large patient populations with depressive and anxiety disorders.

In a meta-review of depressive subtyping models, Baumeister argued that the main obstacle to research on SAD as a distinct subtype of depression is the lack of studies comparing patients with and without SAD in terms of a specific clinical picture, bio-psychosocial correlates and specific treatment responsiveness. ${ }^{2}$

\section{Aims}

In answer to the call for comparative studies within patient populations, we aimed to compare the clinical, demographic and 
personality characteristics of persons with SAD with those of persons with non-seasonal affective disorders (non-SADs) and healthy controls (HC).

Therefore, we first assessed the prevalence of SAD and sub -SAD in a well-described population with affective disorders and $\mathrm{HC}$ and recorded to what diagnostic groups they belonged. Second, we compared the clinical characteristics of participants with SAD and sub-SAD with those of participants with lifetime non-SADs, including bipolar disorders (BPDs), and HC. Third, we zoomed in on participants with SAD and participants with a lifetime depressive disorder or a lifetime comorbid anxiety and depressive disorder (ADD). We compared their clinical characteristics and the seasonal distribution of the scores on a depression questionnaire and two anxiety questionnaires. Finally, we compared the seasonal distribution of depressive episodes (current MDD) in participants with and without SAD.

\section{Method}

The study was conducted using data from the Netherlands Study of Depression and Anxiety (NESDA) (http://www.nesda.nl). ${ }^{1}$ NESDA is an ongoing multisite naturalistic longitudinal cohort study among 2981 adults (18-65 years), aimed at describing the long-term course and consequences of depressive and anxiety disorders. The NESDA sample is stratified by setting community, primary care and specialised mental healthcare. Across recruitment settings, uniform inclusion and exclusion criteria were used. The NESDA sample included participants with a range of psychopathology: those with no lifetime anxiety or depressive disorders (HC), and those with a current first or recurrent depressive disorder (MDD or dysthymic disorder) or anxiety disorder (panic disorder with or without agoraphobia, agoraphobia, social phobia or generalised anxiety disorder). Patients with a clinically overt psychotic disorder, BPD, obsessive-compulsive disorder, or severe substance use disorder, and persons not fluent in Dutch were excluded from the baseline assessment.

In this study, the identification of participants suffering from SAD and sub-SAD was based on the SPAQ, which was administered at the 1-year follow-up measurement. The diagnoses according to the criteria of the Diagnostic and Statistical Manual of Mental Disorders (DSM-IV) and the symptom and personality questionnaires were established one year later in the 2-year faceto-face follow-up interview. Measurements for this study started in September 2005 and lasted until February 2008.

\section{Measures}

The identification of participants suffering from SAD and sub-SAD was based on the SPAQ. The SPAQ is a self-rating screening instrument for SAD that retrospectively measures variation in mood and behaviour by month. ${ }^{11}$ The psychometric properties of the SPAQ are acceptable with test-retest reliability varying from 0.58 to 0.87 , internal consistency varying from 0.74 to 0.82 , specificity varying from 73 to $94 \%$ and sensitivity varying from 31.8 to $94 \%$ in different studies. ${ }^{13-16}$

The criteria for SAD and sub-SAD for the SPAQ have been formulated by Kasper et al. ${ }^{12}$ The SPAQ applies the following three criteria that have to be met to reach the diagnosis of SAD:

(1) The Global Seasonality Scale (GSS) provides a composite measure for change in mood, social activities, appetite, sleep, weight and energy across the seasons. Scales range from (0) 'no change' to (4) 'extremely marked change'. The total score ranges from 0 to 24 . We used the Kasper introduced and most widely used cut-off score of 11 for the self-report version of the SPAQ. ${ }^{12}$

(2) A second criterion for SAD is based on the question whether seasonal changes are considered a problem. The response possibilities range from $0=$ no problem to $5=$ a disabling problem. A score of at least 2 (a moderate problem) is necessary to reach the SAD threshold.

(3) Finally, the timing of the seasonal problems (summer or winter) is determined by asking in which months participants feel worst (the 'window').

In this study, we defined the window for SAD (winter type) positive if participants reported that they usually feel worst in the winter months (December and/or January and/or February) and not in the summer months (June and /or July and/or August). Sub-SAD is defined as a cluster of seasonal complaints that are not severe enough to allow for a diagnosis of SAD. The criteria for sub-SAD are a GSS of 9 or 10 for the self-report version of the SPAQ, regardless of whether the participant considers the seasonal changes to be a problem or not, or a GSS of at least 11 and 'no' or 'mild' problems with the seasonal changes. ${ }^{12}$ The window is the same as for SAD.

In the 2-year follow-up interview, the Composite International Diagnostic Interview (CIDI) (WHO version 2.1) was used to establish current (last month) and lifetime diagnoses of depressive and anxiety disorders according to DSM-IV criteria.

The CIDI is used worldwide, and WHO field research has found high interrater reliability, high test-retest reliability and high validity for depressive and anxiety disorders. ${ }^{1}$ The bipolar section of the CIDI was included in this interview to identify participants with a lifetime BPD. The dates of the 2-year follow-up interview were recorded and were categorised into the four seasons (spring: March 21-June 20, summer: June 21-September 20, autumn: September 21-December 20 and winter: December 21-March 20).

Clinical characteristics of the participants were assessed together with the CIDI using the following instruments:

(1) The Inventory of Depressive Symptoms, 30-item self-report version (IDS), was used to assess the severity of depression. ${ }^{1}$ The IDS was also used to specify atypical and melancholic features of depressive symptoms based on DSM-IV criteria. For atypical features, the algorithm of Novick et $a l^{17}$ was used, identifying participants with mood reactivity and two or more of the following symptoms: hyperphagia, hypersomnia, leaden paralysis and interpersonal rejection sensitivity. In NESDA, a small adaptation for the interpersonal rejection sensitivity item threshold value was used. For the melancholic subtype, the algorithm of Khan et al was used to identify participants lacking mood reactivity and loss of pleasure in (almost) all activities. They also had to report more than three of the following symptoms: distinct quality of depressed mood, mood is worse in the morning, early morning awakening of at least $1 \mathrm{~h}$ before usual time, psychomotor retardation or agitation, significant anorexia or weight loss, and excessive or inappropriate guilt. ${ }^{18}$ These two variables, atypical and melancholic features, were calculated regardless of the presence of a current MDD diagnosis.

(2) The Beck Anxiety Inventory (BAI), a 21-item self-report instrument, was used to assess overall severity of anxiety. ${ }^{1}$ The 15-item self-report version of the Fear Questionnaire (FQ) was used to measure severity of fear and avoidance. ${ }^{1}$

(3) The 60-item NEO Five-Factor Inventory was used to measure five personality domains: neuroticism, extraversion, agreeableness, conscientiousness and openness to experience. ${ }^{1}$ Current antidepressant, anxiolytic and antipsychotic 
medication use was registered, based on drug-container inspection of all the drugs used in the past month (on at least $50 \%$ of days), and classified according to the World Health Organization Anatomical Therapeutic Chemical classification.

Percentage of time with depressive, anxiety and avoidance symptoms during the past 2 years was assessed with the Life Chart interview that uses a calendar approach to measure duration of symptoms.

\section{Participants}

In our first analysis, we used the SPAQ, assessed at the 1-year follow-up measurement, to establish the frequency of SAD and subSAD and we recorded to what diagnostic groups as assessed in the 2-year follow-up CIDI interview the participants belonged.

We defined a group of participants with a current (1 month) MDD. Next, we defined five mutually exclusive groups according to the DSM-IV lifetime diagnoses: (1) depressive disorder, that is, MDD and/or dysthymic disorder (D); (2) anxiety disorder (A); (3) comorbid anxiety and depressive disorder (AD); (4) BPD; and (5) HC.

In our second analysis, we compared participants with SAD and sub-SAD with participants with lifetime non-SADs. For this goal, participants were exclusively assigned to one of the seven groups: (1) SAD; (2) sub-SAD; (3) BPD and no (sub-)SAD (BPD-NS); (4) depressive disorder, that is, MDD and/or dysthymic disorder and no (sub-)SAD (D-NS); (5) anxiety disorder and no (sub-)SAD (A-NS); (6) comorbid ADD, no (sub-)SAD (AD-NS); and (7) HC and no (sub-) SAD (HC-NS).

In our third analysis, demographic and clinical characteristics of participants with SAD were compared with those of participants with a lifetime depressive disorder or a lifetime comorbid ADD, and no (sub)-SAD (ADD-NS).

In our fourth analysis, we compared the seasonal distribution of the scores on the IDS, BAI and FQ of participants with SAD to ADD-NS.

In our fifth analysis, participants with a current MDD and SAD (MDD-S) were compared to participants with a current MDD and no (sub-)SAD (MDD-NS).

\section{Statistical analysis}

Pairwise comparisons were conducted for SAD versus non-SAD. Groups were compared using $t$-tests for continuous variables and chi-square tests for discrete variables.

Logistic regression analyses with age and gender as covariates were used to determine which demographic variables (North European descent, married, divorced, years of education, employment status, income $<€ 800$, income $<€ 1400$ ), which psychopathological variables were present last year and last month (MDD, dysthymia, social phobia, panic disorder with agoraphobia, panic disorder without agoraphobia, agoraphobia, generalised anxiety disorder) and which clinical variables (mean IDS, atypical and melancholic features of IDS, BAI, FQ, use of antipsychotic drugs, use of anxiolytic drugs, use of antidepressant drugs, neuroticism, extraversion, openness, agreeableness and conscientiousness, percent of time with symptoms of depression, anxiety or both depression and anxiety) significantly predicted the presence of $\mathrm{SAD}$ versus $\mathrm{ADD}-\mathrm{NS}$. These variables were subsequently entered together in a multivariate logistic regression analysis. Variables that did not predict the presence of SAD were removed one by one. A threshold of 0.05 was used in order to minimise the risk of type 1 errors.
Analysis of variance (ANOVA) was used to test whether there was a difference in IDS scores (2-year follow-up assessment) across seasons in the SAD group versus the ADD-NS group. Season (spring, summer, autumn, winter), group (SAD and ADD-NS) and the interaction between season and group were used as predictors in this model.

In logistic regression analyses with age and gender as covariates, we used the same variables as described in the comparison of $\mathrm{SAD}$ and $\mathrm{AD}-\mathrm{NS}$ to determine which variables significantly predicted the presence of MDD-S versus MDD-NS. ANOVA was used to test whether there was a difference in IDS scores across seasons in the MDD-S group versus the MDD-NS group. Finally, a chisquare test was used to test whether there was a difference in frequency distribution of MDD-S and MDD-NS across the seasons.

Analyses were conducted using SPSS version 22 statistical software (SPSS Inc., Chicago, Illinois). A two-sided $P$-value of 0.05 was used as the significance level with no correction for multiple comparison.

\section{Ethics statement}

The study protocol of NESDA was approved by the Ethical Review Boards of the VU University Medical Center, the Leiden University Medical Center and the University Medical Center Groningen. After full verbal and written information about the study, written informed consent was obtained from all participants at the start of baseline assessment. A full ethics statement of NESDA and detailed information on objectives and methods of NESDA were published elsewhere.

\section{Results}

Of the original 2981 participants in the NESDA study, 536 (18\%) participants did not return the 1-year follow-up questionnaire containing the SPAQ questionnaire and 99 participants had missing scores on the SPAQ. These participants were excluded from the analysis. Of the remaining 2346 participants, 161 participants (5.4\%) did not participate in the interview at the 2-year follow-up, resulting in 2185 participants included in this analyses. In this sample, the proportion of women (67.5\%) did not significantly deviate from the proportion of women $(66.4 \%)$ in the overall sample of NESDA. Of the 2185 participants, 356 were diagnosed with D, 241 were diagnosed with A, 1021 with $\mathrm{AD}$ and 91 with BPD (Table 1). Four hundred and seventy-six participants (HC) did not have a lifetime CIDI diagnosis of a depressive, anxiety or BPD. Of the 2185 participants 283 were diagnosed with MDD.

\section{Distribution of SAD across CIDI diagnoses}

According to the Kasper criteria, 100 (4.6\%) of the 2185 participants suffered from SAD. For men and women, the percentages were 3.8 and $4.9 \%$, respectively. Sub-SAD according to the Kasper criteria was present for $149(6.8 \%)$ participants: 43 (6.1\%) men and 106 (7.2\%) women.

Table 1 shows to which diagnostic groups SAD and sub-SAD participants belonged according to the CIDI interview. Highest percentages were seen in the $\mathrm{BPD}$ and $\mathrm{AD}$ groups, intermediate percentages for D and A groups, and lowest percentages for the HC group. Of the 1377 participants with a lifetime depressive disorder or a lifetime comorbid ADD, 6.0\% fulfilled the SPAQ criteria of SAD and $8.1 \%$ fulfilled the SPAQ criteria of sub-SAD.

Of the 283 participants with an MDD, 36 (12.7\%) fulfilled the SPAQ criteria of SAD and $32(11.3 \%)$ fulfilled the criteria of sub-SAD. 


\begin{tabular}{|c|c|c|c|c|c|c|}
\hline & $\begin{array}{c}D^{b} \\
n=356\end{array}$ & $\begin{array}{c}A^{b} \\
n=241\end{array}$ & $\begin{array}{c}A D^{b} \\
n=1021\end{array}$ & $\begin{array}{l}\mathrm{BPD}^{\mathrm{b}} \\
n=91\end{array}$ & $\begin{array}{c}H C^{b} \\
n=476\end{array}$ & $\begin{array}{c}\text { Total } \\
n=2185\end{array}$ \\
\hline & \multicolumn{6}{|c|}{$n(\%)$} \\
\hline$S A D^{a}$ & 14 (3.9\%) & $4(1.7 \%)$ & 69 (6.8\%) & 11 (12.1\%) & 2 (0.4\%) & 100 (4.6\%) \\
\hline sub-SADa & 21 (5.9\%) & $16(6.6 \%)$ & 90 (8.8\%) & $11(12.1 \%)$ & 11 (2.3\%) & 149 (6.8\%) \\
\hline
\end{tabular}

\section{SAD compared with non-SADs (lifetime diagnoses) and HC: demographic and clinical characteristics}

Table 2 shows the demographic and clinical characteristics of the 2185 participants in seven diagnostic groups.

The proportion of men was higher in the BPD-NS and HC-NS group compared to SAD. Compared to SAD, participants in the sub -SAD group were younger. Participants in the SAD group were less frequently employed than participants in the other groups (except for BPD-NS) but the difference was not significant for $\mathrm{AD}-\mathrm{NS}$ and BPD-NS. Like BPD-NS, participants with SAD were most likely to have an income below $€ 1400$ per month.

Participants in the SAD, BPD-NS and AD-NS groups scored highest in terms of psychopathology in the last month and in terms of psychopathology in the past year. At the 2-year follow-up, participants in the SAD group scored higher than the other groups on the IDS, BAI and FQ but there was no significant difference between SAD and BPD-NS.

\section{SAD compared with lifetime depressive disorders: demographic and clinical characteristics}

The SAD group consisted of 100 participants. The ADD-NS group consisted of 1183 participants diagnosed with a lifetime depressive disorder or a lifetime comorbid ADD, and no SAD or sub-SAD.

The logistic regression analyses showed that the following variables predicted the presence of SAD: age, employment status, income category below $€ 1400$ per month, neuroticism, MDD last year, agoraphobia last year, generalised anxiety disorder last year, mean IDS scores (2-year follow-up assessment), melancholic features of the IDS, FQ mean score, BAI anxiety mean score and use of antipsychotics.

In the successive multivariate logistic regression analysis, we did not include the BAI because the IDS and the BAI showed a high correlation of 0.80 . We also did not include 1-month diagnoses because of the overlap between 2-year and 1-month diagnoses.

In the last model, after removing the variables that were not significant, the variables age, income below $€ 1400$, MDD last year, agoraphobia and high melancholic features on the IDS significantly predicted the presence of SAD versus ADD-NS (Table 3).

\section{SAD compared with lifetime depressive disorders: seasonality of depressive and anxiety symptoms}

Figure 1 shows the scores on the IDS (2-year follow-up assessment) in the four seasons for SAD and ADD-NS. The figure suggests that IDS scores in autumn and winter were higher than in spring and summer for the SAD group. However, ANOVA showed that there was no significant interaction between the seasons and the groups: $F(3,1266)=0.82, P=0.48$, meaning that the seasonal differences in IDS scores were not different for SAD versus ADD-NS. After removal of the interaction term, ANOVA showed that there was also no significant overall effect for the seasons: $F(3,1266)=1.84$, $P=0.14$. In this last model, the mean IDS score of the SAD group was significantly higher than the mean score of the ADD-NS group: $F(1,1266)=21.51, P<0.01$. Also for the scores on the BAI and the FQ, there were no significant seasonal differences between the groups (data not shown).

\section{Current MDD with SAD compared with current MDD without SAD}

The MDD-S group consisted of 36 participants. The MDD-NS group consisted of 215 participants. Table 4 shows the seasonal distribution of MDD-S and MDD-NS. A chi-square test showed that there was no statistical significant difference in seasonal distribution between MDD-S and MDD-NS: $\chi^{2}(3)=5.876, P=0.118$.

In the logistic regression analyses and subsequent multivariate logistic regression analysis, only the melancholic features significantly predicted the presence of MDD-S versus MDD-NS, with an odds ratio of 2.39 (95\% CI 1.00-5.70), $P=0.049$.

ANOVA showed that there were no statistically significant seasonal differences in IDS scores for MDD-S versus MDD-NS: $F(3$, 246) $=0.21, P=0.89$. After removal of the interaction term, ANOVA showed that there was no significant overall effect for the seasons: $F(3,246)=1.34, P=0.26$. In this last model, there was also no significant difference in mean IDS score between MDD-S and MDD-NS: $F(3.246)=0.17, P=0.68$.

Also for the scores on the BAI and the FQ, there were no significant seasonal differences between the groups (data not shown).

\section{Discussion}

In this large naturalistic study among participants with affective disorders and HC, the overall prevalence of SAD and sub-SAD was comparable to the prevalence in the general population in the Netherlands: $4.6 \%$ for SAD versus $3.1 \%$ in the general population and $6.8 \%$ for sub-SAD versus $8.5 \%$ in the general population. ${ }^{10}$

The prevalence of SAD was low within the bipolar group (12.1\%) and anxiety disorder group (1.7\%) when compared with studies that also used the SPAQ in a clinical population (BPD 27.3\%, panic disorder $30.1 \%){ }^{19-21}$ For the bipolar group, an explanation for the low prevalence of SAD might be that the bipolar group in this study was not a fully representative sample of patients with a BPD, because our bipolar group consisted of participants with no clinical history of BPD at baseline measurement who were diagnosed at the 2-year follow-up measurement with the CIDI. ${ }^{22}$ For the anxiety disorder group, an explanation might be that Marriot studied exclusively patients with a panic disorder and used a cut-off score of 10 on the GSS for SAD. ${ }^{20}$

The prevalence of SAD within the group of participants suffering from current MDD (12.7\%) was comparable to the finding of Levitt et $_{\text {al }}{ }^{23}(11 \%)$ in a Canadian community sample. ${ }^{23}$

In our study, participants suffering from SAD presented a severe clinical picture. Like participants with a lifetime BPD and 
Table 2 Socio-demographic, psychopathological and clinical variables, with pairwise comparison of SAD versus the other groups

\begin{tabular}{|c|c|c|c|c|c|c|c|c|}
\hline & $\begin{array}{l}\text { BPD-NS } \\
(n=69)\end{array}$ & $\begin{array}{c}\text { D-NS } \\
(n=321)\end{array}$ & $\begin{array}{c}\text { A-NS } \\
(n=221)\end{array}$ & $\begin{array}{l}\text { AD-NS } \\
(n=862)\end{array}$ & $\begin{array}{l}\text { HC-NS } \\
(n=463)\end{array}$ & SAD (100) & $\begin{array}{l}\text { Sub-SAD } \\
(149)\end{array}$ & $\begin{array}{c}\text { Total } \\
(n=2185)\end{array}$ \\
\hline \multicolumn{9}{|l|}{ Socio-demographic variables } \\
\hline $\begin{array}{l}\text { Age at baseline (years), } \\
\text { mean (s.d.) }\end{array}$ & $42.9(11.7)$ & $43.6(13.0)$ & $43.4(13.5)$ & $43.5(12.3)$ & $42.5(14.4)$ & $41.0(12.7)$ & $\begin{array}{c}36.8 \\
(11.8)^{\star *}\end{array}$ & $42.7(13.1)$ \\
\hline Female, $n(\%)$ & $38(55.1 \%)^{*}$ & $207(64.5 \%)$ & $143(64.7 \%)$ & $619(71.8 \%)$ & $\begin{array}{c}289 \\
(62.4 \%)^{*}\end{array}$ & $73(73.0 \%)$ & $106(71.1 \%)$ & $\begin{array}{c}1475 \\
(67.5 \%)\end{array}$ \\
\hline $\begin{array}{l}\text { North European } \\
\text { descent, } n(\%)\end{array}$ & $67(97.1)$ & $309(96.3 \%)$ & $211(95.5 \%)$ & 825 (95.7\%) & $\begin{array}{c}450 \\
(97.2 \%)^{*}\end{array}$ & 92 (92.0\%) & $142(95.3 \%)$ & $\begin{array}{c}2096 \\
(95.9 \%)\end{array}$ \\
\hline Married (\%) & 32 (46.4\%) & 131 (40.8\%) & $\begin{array}{c}106 \\
(48.0 \%)^{*}\end{array}$ & 347 (40.3\%) & $\begin{array}{c}221 \\
(47.7 \%)^{*}\end{array}$ & $34(34.0 \%)$ & 44 (29.5\%) & 915 (41.9\%) \\
\hline Divorced (\%) & $9(13.0 \%)$ & $59(18.4 \%)$ & $22(10.0 \%)^{*}$ & $147(17.1 \%)$ & $37(8.0 \%)^{\star *}$ & $18(18.0 \%)$ & $23(15.4 \%)$ & $315(14.4 \%)$ \\
\hline $\begin{array}{l}\text { Years of education, } \\
\text { mean (s.d.) }\end{array}$ & $12.0(3.6)$ & $13.0(3.3)$ & 12.9 (3.3) & $12.2(3.3)$ & 13.2 (3.3) & $12.6(3.0)$ & $12.4(3.0)$ & $12.6(3.3)$ \\
\hline Employed, $n(\%)^{\mathrm{a}}$ & 29 (43.3\%) & $\begin{array}{c}205 \\
(65.9 \%)^{*}\end{array}$ & $\begin{array}{c}142 \\
(66.4 \%)^{*}\end{array}$ & $510(60.6 \%)$ & $\begin{array}{c}312 \\
(69.6 \%)^{*}\end{array}$ & $52(52.5 \%)$ & $\begin{array}{c}106 \\
(71.6 \%)^{*}\end{array}$ & $\begin{array}{c}1356 \\
(63.7 \%)\end{array}$ \\
\hline $\begin{array}{l}\text { Income }<€ 800 \text { per } \\
\text { month, } n(\%)^{b}\end{array}$ & 7 (10.1\%) & 12 (3.8\%) & $6(2.7 \%)$ & $37(4.3 \%)$ & $29(6.3 \%)$ & $5(5.2 \%)$ & $7(4.8 \%)$ & $103(4.8 \%)$ \\
\hline $\begin{array}{l}\text { Income }<€ 1400 \text { per } \\
\text { month, } n(\%)^{b}\end{array}$ & 21 (30.4\%) & $\begin{array}{c}55 \\
(17.2 \%)^{\star *} \\
\end{array}$ & $41(18.7 \%)^{*}$ & $\begin{array}{c}184 \\
(21.5 \%)^{*}\end{array}$ & $\begin{array}{c}68 \\
(14.9 \%)^{\star *}\end{array}$ & $34(35.1 \%)$ & $31(21.1 \%)^{*}$ & 434 (20.1\%) \\
\hline \multicolumn{9}{|c|}{ Psychopathology last year (2-year follow-up measurement - CIDI) } \\
\hline $\begin{array}{l}\text { Major depressive } \\
\text { disorder, } n(\%)\end{array}$ & 49 (71.0\%) & $\begin{array}{c}71 \\
(21.1 \%)^{\star *}\end{array}$ & - & $\begin{array}{c}323 \\
(37.5 \%)^{\star \star}\end{array}$ & - & $57(57.0 \%)$ & $64(43.0 \%)^{*}$ & 564 (25.8\%) \\
\hline Dysthymia, n (\%) & $22(31.9 \%)^{*}$ & $14(4.4 \%)^{* *}$ & - & 139 (16.1\%) & - & 18 (18.0\%) & 15 (10.1\%) & 208 (9.5\%) \\
\hline Social Phobia, $n$ (\%) & 17 (24.6\%) & - & 32 (14.5\%) & 203 (23.5\%) & - & $23(23.0 \%)$ & $36(24.2 \%)$ & $311(14.2 \%)$ \\
\hline $\begin{array}{l}\text { Panic disorder with } \\
\text { agoraphobia, } n(\%)\end{array}$ & $12(17.4 \%)^{\star}$ & - & $11(5.0 \%)$ & 80 (9.3\%) & - & $7(7.0 \%)$ & $10(6.7 \%)$ & 120 (5.5\%) \\
\hline $\begin{array}{l}\text { Panic disorder without } \\
\text { agoraphobia, } n(\%)\end{array}$ & $12(17.4 \%)^{*}$ & - & $18(8.1 \%)$ & $92(10.7 \%)$ & - & $6(6.0 \%)$ & $14(9.4 \%)$ & 142 (6.5\%) \\
\hline Agoraphobia, $n$ (\%) & $8(11.6 \%)$ & - & $19(8.6 \%)$ & $86(10.0 \%)$ & - & $14(14.0 \%)$ & $12(8.1 \%)$ & 139 (6.4\%) \\
\hline $\begin{array}{l}\text { Generalised anxiety } \\
\text { disorder, } n(\%)\end{array}$ & $10(14.5 \%)$ & - & $8(3.6 \%)^{* *}$ & 130 (15.1\%) & - & 18 (18.0\%) & $13(8.7 \%)^{*}$ & 179 (8.2\%) \\
\hline \multicolumn{9}{|c|}{ Psychopathology last month (2-year follow-up measurement - CIDI) } \\
\hline $\begin{array}{l}\text { Major depressive } \\
\text { disorder, } n(\%)\end{array}$ & $23(33.3 \%)$ & $27(8.4 \%)^{\star *}$ & - & $\begin{array}{c}165 \\
(19.1 \%)^{* *}\end{array}$ & - & $36(36.0 \%)$ & $32(21.5 \%)^{*}$ & $283(13.0 \%)$ \\
\hline Dysthymia, $n$ (\%) & $18(26.1 \%)$ & $10(3.1 \%)^{* *}$ & - & $110(12.8 \%)$ & - & $17(17 \%)$ & $11(7.4 \%)^{*}$ & $166(7.6 \%)$ \\
\hline Social phobia, $n(\%)$ & $16(23.2 \%)$ & - & $26(11.8 \%)^{*}$ & $160(18.6 \%)$ & - & $21(21.0 \%)$ & $31(20.8 \%)$ & 254 (11.6\%) \\
\hline $\begin{array}{l}\text { Panic disorder with } \\
\text { agoraphobia, } n(\%)\end{array}$ & $6(8.7 \%)$ & - & $7(3.2 \%)$ & $61(7.1 \%)$ & - & $6(6.0 \%)$ & $10(6.7 \%)$ & 90 (4.1\%) \\
\hline $\begin{array}{l}\text { Panic disorder without } \\
\text { agoraphobia, } n(\%)\end{array}$ & 7 (10.1\%) & - & $10(4.5 \%)$ & $58(6.7 \%)$ & - & $3(3.0 \%)$ & $12(7.4 \%)$ & 89 (4.1\%) \\
\hline Agoraphobia, $n$ (\%) & $4(5.8 \%)$ & - & $10(4.5 \%)^{*}$ & $61(7.1 \%)$ & - & $11(11.0 \%)$ & $11(7.4 \%)$ & 97 (4.4\%) \\
\hline $\begin{array}{l}\text { Generalised anxiety } \\
\text { disorder, } n(\%)\end{array}$ & $7(10.1 \%)$ & - & $7(3.2 \%)^{* *}$ & $93(10.8 \%)$ & - & $14(14.0 \%)$ & $11(7.4 \%)$ & $132(6.0 \%)$ \\
\hline \multicolumn{9}{|c|}{ Symptoms of depression and anxiety (2-year follow-up measurement) } \\
\hline IDS, mean (s.d. $)^{c}$ & $26.8(14.4)$ & $12.7(9.1)^{\star \star \star}$ & $12.4(8.2)^{\star \star}$ & $20.0(12.1)^{\star}$ & $6.1(5.2)^{* *}$ & $24.0(13.0)$ & $19.5(10.7)^{\star}$ & $15.5(11.9)$ \\
\hline IDS atypical featuresc & $10(14.7 \%)$ & $9(2.8 \%)^{* *}$ & $4(1.8 \%)^{\star *}$ & $71(8.4 \%)$ & $0(0.0 \%)^{* *}$ & $12(12.4 \%)$ & $10(6.9 \%)$ & $116(5.4 \%)$ \\
\hline $\begin{array}{l}\text { IDS melancholic } \\
\text { features }^{d}\end{array}$ & $10(14.7 \%)$ & $2(0.6 \%)^{* *}$ & $2(0.9 \%)^{* *}$ & $25(3.0 \%)^{*}$ & $0(0.0 \%)^{\star *}$ & 9 (9.3\%) & 5 (3.5\%) & 53 (2.5\%) \\
\hline BAl, mean (s.d.)c & $16.1(12.0)$ & $5.7(5.8)^{\star *}$ & $7.4(7.4)^{\star *}$ & $11.2(9.0)^{*}$ & $2.9(3.7)^{\star \star *}$ & $14.0(10.1)$ & $11.1(8.8)^{\star}$ & $8.5(8.6)$ \\
\hline $\mathrm{FQ}$, mean (s.d.) ${ }^{e}$ & $24.7(19.8)$ & $\begin{array}{c}11.6 \\
(11.2)^{\star \star}\end{array}$ & $\begin{array}{c}17.0 \\
(13.6)^{\star *}\end{array}$ & $24.8(18.6)^{\star}$ & $9.0(8.9)^{\star *}$ & $29.2(20.0)$ & $25.2(19.4)$ & $18.9(17.2)$ \\
\hline \multicolumn{9}{|l|}{ Medication use } \\
\hline $\begin{array}{l}\text { Use of antipsychotic } \\
\text { drug, } n(\%)\end{array}$ & $10(14.5 \%)$ * & $4(1.2 \%)^{*}$ & $1(0.5 \%)^{* *}$ & $13(1.5 \%)^{\star}$ & $0(0.0 \%)^{* *}$ & $5(5.0 \%)$ & $1(0.7 \%)^{\star}$ & 34 (1.6\%) \\
\hline $\begin{array}{l}\text { Use of anxiolytica drug, } \\
n(\%)\end{array}$ & $17(24.6 \%)^{*}$ & $8(2.5 \%)^{*}$ & $20(9.0 \%)$ & $96(11.1 \%)$ & $5(1.1 \%)^{* *}$ & $10(10.0 \%)$ & $16(10.7 \%)$ & $172(7.9 \%)$ \\
\hline $\begin{array}{l}\text { Use of antidepressant } \\
\text { drug, } n(\%)\end{array}$ & $33(47.8 \%)$ & $\begin{array}{c}51 \\
(15.9 \%)^{\star *}\end{array}$ & $\begin{array}{c}24 \\
(10.9 \%)^{\star \star}\end{array}$ & 291 (33.8\%) & $5(1.1 \%)^{\star *}$ & $36(36.0 \%)$ & 39 (26.2\%) & 479 (21.9\%) \\
\hline $\begin{array}{l}\text { Global seasonality score, } \\
\text { mean (s.d.) }\end{array}$ & $5.5(4.2) * *$ & $4.0(2.9)^{\star *}$ & $3.2(2.6)^{* *}$ & $4.8(3.2)^{* *}$ & $2.6(2.3)^{\star *}$ & $13.7(2.7)$ & $10.2(1.7)^{\star *}$ & $4.9(3.9)$ \\
\hline \multicolumn{9}{|c|}{$\begin{array}{l}\text { BPD-NS, bipolar disorder (no SAD or sub-SAD); D-NS, any depressive disorder, lifetime diagnosis (no SAD or sub-SAD); A-NS, any anxiety disorder, lifetime diagnosis (no SAD or } \\
\text { sub-SAD); AD-NS, any depressive disorder, lifetime diagnosis + any comorbid anxiety disorder, lifetime diagnosis (no SAD or sub-SAD); HC-NS, healthy control (no SAD or sub-SAD); } \\
\text { SAD, seasonal affective disorder; sub-SAD, sub-seasonal affective disorder; IDS, Inventory of Depressive Symptoms; BAl, Beck Anxiety Inventory; FQ, Fear Questionnaire. Pairwise } \\
\text { comparisons } T \text {-test for continuous variables Chi-square test for discrete variables a. } n=2156 \text { b. } n=2154 \text { C. } n=2151 \text { d. } n=2128 \text { e. } n=2164 \mathrm{f} \text {. } n=2185 \text {. Based on chi-square test for } \\
\text { categorical variables and ANOVA for continuous variables, }{ }^{*} P<0.05{ }^{* *} P<0.01 \text {. }\end{array}$} \\
\hline
\end{tabular}




\begin{tabular}{|c|c|c|c|c|c|c|c|c|}
\hline & \multirow[t]{2}{*}{$\begin{array}{l}\text { Unadjusted odds } \\
\text { ratio } \operatorname{Exp}(B)\end{array}$} & \multicolumn{2}{|c|}{$95 \% \mathrm{Cl}$} & \multirow[t]{2}{*}{ Sig. } & \multirow[t]{2}{*}{$\begin{array}{l}\text { Adjusted odds } \\
\text { ratio } \operatorname{Exp}(B)^{b}\end{array}$} & \multicolumn{2}{|c|}{$95 \% \mathrm{Cl}$} & \multirow[t]{2}{*}{ Sig. } \\
\hline & & Lower & Upper & & & Lower & Upper & \\
\hline Age at 2-year follow-up & 0.984 & 0.968 & 1.000 & 0.047 & 0.983 & 0.966 & 1.000 & 0.052 \\
\hline Female & 1.169 & 0.739 & 1.848 & 0.506 & 1.079 & 0.663 & 1.754 & 0.760 \\
\hline Income $<€ 1400$ per month & 2.114 & 1.360 & 3.284 & 0.001 & 1.711 & 1.076 & 2.722 & 0.023 \\
\hline Major depressive disorder last year & 2.655 & 1.755 & 4.016 & $<0.001$ & 2.586 & 1.649 & 4.056 & $<0.001$ \\
\hline Agoraphobia last year & 2.077 & 1.133 & 3.806 & 0.018 & 1.995 & 1.039 & 3.831 & 0.038 \\
\hline IDS melancholic features & 4.322 & 1.971 & 9.475 & $<0.001$ & 2.732 & 1.195 & 6.245 & 0.017 \\
\hline \multicolumn{9}{|c|}{$\begin{array}{l}\text { IDS, Inventory of Depressive Symptoms; MDD, major depressive disorders; SAD, seasonal affective disorder. a. SAD, seasonal affective disorder according to SPAQ criteria ( } n=94) \text {; } \\
\text { ADD-NS, a lifetime depressive disorder or a lifetime comorbid anxiety and depressive disorder and no SAD or sub-SAD ( } n=1160) \text {. b. Based on multivariate logistic regression analysis } \\
\text { with age and gender as covariates. }\end{array}$} \\
\hline
\end{tabular}

Table 4 Seasonal distribution of current major depressive disorder in participants with and without $S A D^{a, b}$

\begin{tabular}{|lcc|}
\hline & MDD with SAD & MDD without SAD \\
\hline Spring & $7(19.4 \%)$ & $53(24.7 \%)$ \\
\hline Summer & $3(8.3 \%)$ & $39(18.1 \%)$ \\
\hline Autumn & $10(27.8 \%)$ & $67(31.2 \%)$ \\
\hline Winter & $16(44.4 \%)$ & $56(26.0 \%)$ \\
\hline Total & $36(100 \%)$ & $215(100 \%)$ \\
\hline
\end{tabular}

MDD, current major depressive disorder; SAD, seasonal affective disorder. a. In order to enhance the contrast between the groups, 32 participants with MDD and sub-SAD were excluded from this analysis. b. Chi-square test: $P=0.118$.

participants with a lifetime comorbid ADD, the SAD group scored high in terms of psychopathology in the last month and in terms of psychopathology in the past year. In contrast to our findings, SAD has been described previously as a relatively mild variant of depression characterised by an atypical symptom profile and with lower occupational and cognitive impairment than non-seasonal depression. ${ }^{24,25}$ On the contrary, in other studies SAD was associated with high impairment and high comorbidity rates of BPD, phobias and somatoform disorders. ${ }^{5,15,26}$

\section{Seasonality of symptoms, mainly a psychological phenomenon?}

In this study, there was no significant difference between the seasons in scores on psychopathological and clinical variables, neither for participants with any lifetime depressive disorder nor for participants with SAD. Also the seasonal distribution of a current MDD was not significantly different for participants with or without SAD. Finally, there was no statistically significant difference in severity of depressive and anxiety symptoms between participants with a current MDD and SAD and participants with a current MDD and no SAD.

Although a number of studies showed that within clinical populations, patients with SAD experience variation in symptom severity over seasons, ${ }^{21,27}$ other studies had different findings. ${ }^{28,29}$ In a large cohort of bipolar patients, Murray et al ${ }^{30}$ could not find a significant seasonal pattern for depressive symptoms. Furthermore in a systematic review on seasonality and BPD, the association between symptoms and seasonality in BPD was found to be limited..$^{31}$ Also in a large population of out-patient psychiatric patients, no seasonal fluctuation in severity of depressive symptoms could be demonstrated. ${ }^{32}$ Furthermore, there is some concern considering the stability of the diagnosis of SAD. For example, Sakamoto found that only $22 \%$ of the SAD patients consistently showed a

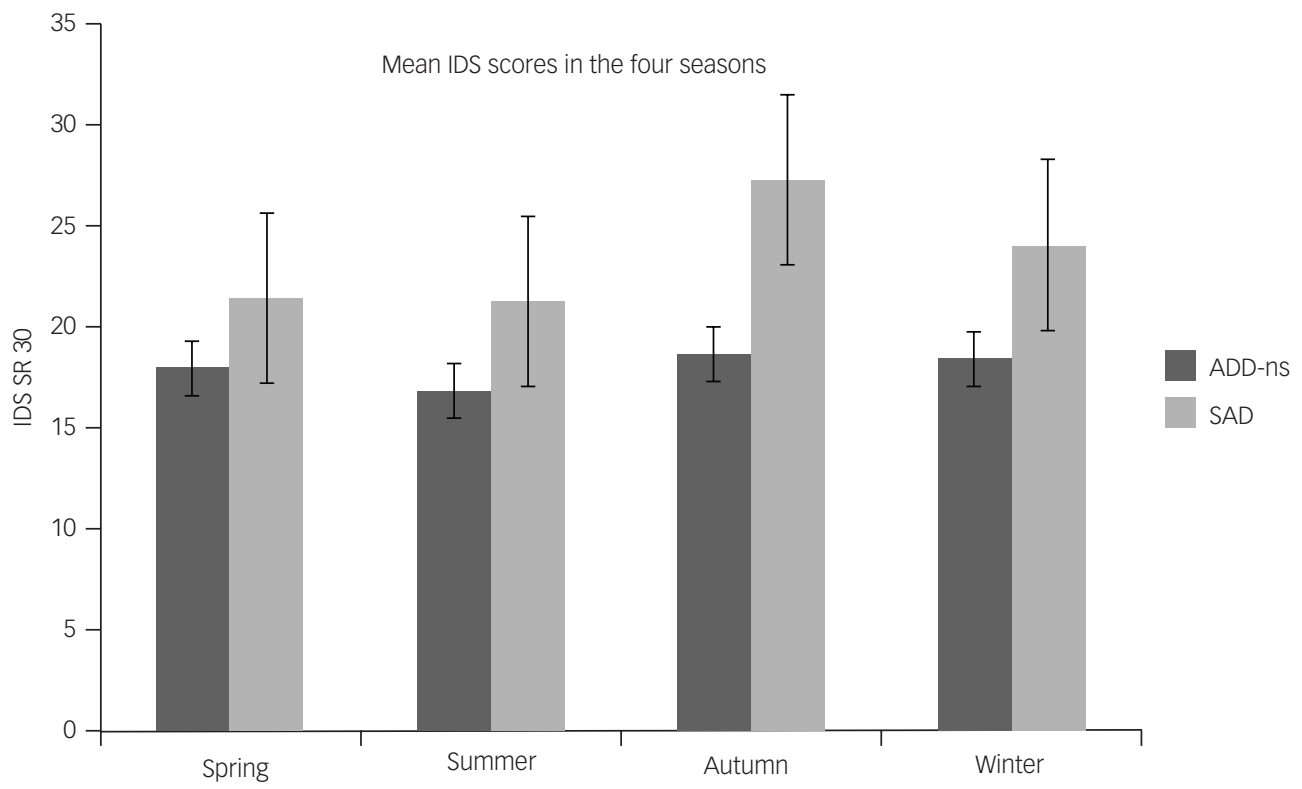

Fig. 1. Depressive symptom scores across the seasons for participants with $S A D$ and participants with $A D D-n s$. 
winter pattern of recurrence of depressive episodes over a 10 -year follow-up period. ${ }^{33}$

It has been argued that discrepant results in the research on SAD might be related to heterogeneity in the pathophysiology of SAD. This heterogeneity then might be explained by the dual vulnerability model, which was first proposed by Young. ${ }^{5,34,35}$ According to this model, the winter worsening in seasonal and non-seasonal affective disorders can be explained by a differential loading on separate seasonal and depression factors. In this model, the seasonal factor has a circadian mechanism with seasonal physiological symptoms, whereas the depression factor is related to psychological vulnerability. Individuals with high levels of seasonality who also have high loadings on the depression factor may not show a pattern of SAD because their higher level of vulnerability to distress may manifest as non-seasonal depressive episodes. ${ }^{5}$

Yet, there could be another explanation for our results. In a previous study, we found that participants with more severe psychopathology more frequently reported seasonality of symptoms. ${ }^{36}$ This study shows that participants in the SAD group scored high on psychopathology throughout the year but also high on the neuroticism scale. An explanation might be that participants who score high on neuroticism and have high levels of psychopathology attribute their symptoms and unhappiness in a greater extent to the seasons than individuals with less severe complaints. Thus, the psychological mechanism of cognitive attribution might be at work when seasonality is subjectively assessed.

Support for this line of thought can be found in the literature concerning the psychological and personality aspects of individuals suffering from SAD. ${ }^{37-39}$ Murray and Bagby found that the tendency to report SAD symptoms co-varied with neuroticism and openness, and with a tendency to attribute mood fluctuations to factors beyond the individual's control. ${ }^{37,39}$ In terms of treatment, Rohan showed that a psychological intervention like cognitivebehavioural therapy was comparably effective as light therapy in an acute episode of depression in SAD but superior to light therapy in two winters following light therapy ${ }^{40}$

\section{Limitations}

In this study, SAD was not assessed according to DSM-IV criteria but based on the SPAQ. The SPAQ seems accurate enough to be used as a screening instrument, to which end it has been used extensively. ${ }^{13,23}$ However, it is recognised that the SPAQ tends to be over-inclusive. ${ }^{13,16}$ One reason for the over-inclusiveness of the SPAQ might be its vulnerability to recall bias, because it is a self-report questionnaire that measures seasonality of mood and behaviour retrospectively and does not check for the presence of a major depressive episode at the time of diagnosing. ${ }^{16,26}$ Second, deriving a binary outcome from a continuous scale can lead to a misclassification bias which might lead to a decrease of the power to detect an association. Therefore, it is possible that we did not detect existing differences between the groups. Another limitation of this study is the lack of repeated measurements within a year, limiting our ability to make inferences regarding prospective or causal effects. A fourth limitation that should be mentioned concerns the bipolar group. At baseline, participants with a clinical history of BPD were excluded. At 2-year follow-up, a group of participants were diagnosed with a BPD. ${ }^{22}$ Those cases of BPD are likely to be mild cases and therefore not a fully representative sample for patients with a BPD.

Participants with SAD, participants with a lifetime BPD and participants with a lifetime comorbid ADD scored highest in terms of psychopathology in the past year. In this study, there was no difference in seasonal distribution of major depressive episodes between participants with or without SAD.
In conclusion, our study suggests that, within a clinical population, SAD is a measure of severity with high levels of symptoms throughout the year and a perceived worsening of symptoms in the winter months. However, more research is needed, especially longterm follow-up studies with regular measurements within the different seasons, including physiological correlates, of patients who are diagnosed with SAD according to DSM-5 criteria.

\section{Wim H. Winthorst, MD, Interdisciplinary Center Psychopathology and Emotion Regulation, University of Groningen, University Medical Center Groningen, Groningen, The Netherlands; Annelieke M. Roest, PhD, Interdisciplinary Center Psychopathology and Emotion Regulation, University of Groningen, University Medical Center Groningen, Groningen, The Netherlands; Elisabeth H. Bos, PhD, Interdisciplinary Center Psychopathology and Emotion Regulation, University of Groningen, University Medical Center Groningen, Groningen, The Netherlands; Ybe Meesters, PhD, Interdisciplinary Center Psychopathology and Emotion Regulation, University of Groningen, University Medical Center Groningen, Groningen, The Netherlands; Brenda W.J.H. Penninx, PhD, Department of Psychiatry/EMGO Institute for Health and Care Research, VU University Medical Center, Amsterdam, The Netherlands; Willem A. Nolen, MD, PhD, Interdisciplinary Center Psychopathology and Emotion Regulation, University of Groningen, University Medical Center Groningen, Groningen, The Netherlands; Peter de Jonge PhD, Interdisciplinary Center Psychopathology and Emotion Regulation, University of Groningen, University Medical Center Groningen, Groningen, The Netherlands.}

Correspondence: Wim H. Winthorst, Department of Psychiatry, University Medical Center Groningen, University of Groningen, Hanzeplein 1, 9700 AB, Groningen, The Netherlands. E-mail: w.h.winthorst@umcg.nl

First received 14 Apr 2017, final revision 7 Jul 2017, accepted 19 Jul 2017

\section{Funding}

The infrastructure for the NESDA study is funded through the Geestkracht program of the Netherlands Organisation for Health Research and Development (Zon-MW, grant number 10-000-1002) and is supported by participating universities and mental health care organisations IVU University Medical Center, GGZ in Geest, Arkin, Leiden University Medical Center, GGZ Rivierduinen, University Medical Center Groningen, Lentis, GGZ Friesland, GGZ Drenthe, IQ Healthcare, Netherlands Institute for Health Services Research (NIVEL) and Netherlands Institute of Mental Health and Addiction (Trimbos)]. An a priori analysis plan for this study was approved by the principal investigator of NESDA and the NESDA board. Because of ethical and legal restrictions, data involving clinical participants are not included in the manuscript or made available in a public repository. However, subject to approval, data are available upon request from the NESDA Data Access Committee (nesda@ggzingeest.nl).

\section{References}

1 Penninx BW, Beekman AT, Smit JH, Zitman FG, Nolen WA, Spinhoven P, et al. The Netherlands Study of Depression and Anxiety (NESDA): rationale, objectives and methods. Int J Methods Psychiatr Res 2008; 17: 121-40.

2 Baumeister H, Parker G. Meta-review of depressive subtyping models. J Affect Disord 2012; 139: 126-40.

3 Golden RN, Gaynes BN, Ekstrom RD, Hamer RM, Jacobsen FM, Suppes T, et al. The efficacy of light therapy in the treatment of mood disorders: a review and meta-analysis of the evidence. Am J Psychiatry 2005; 162: 656-62

4 Ravindran AV, Lam RW, Filteau MJ, Lesperance F, Kennedy SH, Parikh SV, et al. Canadian Network for Mood and Anxiety Treatments (CANMAT) clinical guidelines for the management of major depressive disorder in adults. V. Complementary and alternative medicine treatments. J Affect Disord 2009; 117 (suppl 1): S54-64.

5 Westrin A, Lam RW. Seasonal affective disorder: a clinical update. Ann Clin Psychiatry 2007; 19: 239-46.

6 Eastwood MR, Peter AM. Epidemiology and seasonal affective disorder. Psychol Med 1988; 18: 799-806

7 Traffanstedt MK, Mehta S, LoBello SG. Major depression with seasonal variation: is it a valid construct? Clin Psychol Sci 2016; 4: 825-34.

8 Hansen V, Skre I, Lund E. What is this thing called "SAD"? A critique of the concept of seasonal affective disorder. Epidemiol Psichiatr Soc 2008; 17: 120-7.

9 Winkler D, Pjrek E, Spies M, Willeit M, Dorffner G, Lanzenberger R, et al. Has the existence of seasonal affective disorder been disproven? J Affect Disord 2017; 208: 54-5.

10 Mersch PP Middendorp HM, Bouhuys AL, Beersma DG, van den Hoofdakker RH. The prevalence of seasonal affective disorder in The Netherlands: a prospective and retrospective study of seasonal mood variation in the general population. Biol Psychiatry 1999; 45: 1013-22.

11 Rosenthal NE, Genhart MJ, Sack DA, Skerwer RG, Wehr TA. Seasonal affective disorder and its relevance for the understanding and treatment of bulimia. In 
The Psychobiology of Bulimia (eds JI Hudson, HG Pope): 205-28. American Psychiatric Press.

12 Kasper S, Wehr TA, Bartko JJ, Gaist PA, Rosenthal NE. Epidemiological findings of seasonal changes in mood and behavior. A telephone survey of Montgomery County, Maryland. Arch Gen Psychiatry 1989; 46: 823-33.

13 Mersch PP, Vastenburg NC, Meesters $Y$, Bouhuys AL, Beersma DG, van den Hoofdakker $\mathrm{RH}$, et al. The reliability and validity of the Seasonal Pattern Assessment Questionnaire: a comparison between patient groups. I Affect Disord 2004; 80: 209-19.

14 Magnusson A. Validation of the Seasonal Pattern Assessment Questionnaire (SPAQ). J Affect Disord 1996; 40: 121-9.

15 Young MA, Blodgett C, Reardon A. Measuring seasonality: psychometric properties of the Seasonal Pattern Assessment Questionnaire and the Inventory for Seasonal Variation. Psychiatry Res 2003; 117: 75-83.

16 Pjrek E, Baldinger-Melich P, Spies M, Papageorgiou K, Kasper S, Winkler D. Epidemiology and socioeconomic impact of seasonal affective disorder in Austria. Eur Psychiatry 2016; 32: 28-33.

17 Novick JS, Stewart JW, Wisniewski SR, Cook IA, Manev R, Nierenberg AA, et al. Clinical and demographic features of atypical depression in outpatients with major depressive disorder: preliminary findings from STAR*D. J Clin Psychiatry 2005; 66: 1002-11.

18 Khan AY, Carrithers J, Preskorn SH, Lear R, Wisniewski SR, John Rush A, et al. Clinical and demographic factors associated with DSM-IV melancholic depression. Ann Clin Psychiatry 2006; 18: 91-8.

19 Shand AJ, Scott NW, Anderson SM, Eagles JM. The seasonality of bipolar affective disorder: comparison with a primary care sample using the Seasonal Pattern Assessment Questionnaire. J Affect Disord 2011; 132: 289-92.

20 Marriott PF, Greenwood KM, Armstrong SM. Seasonality in panic disorder. J Affect Disord 1994; 31: 75-80.

21 Ohtani T, Kaiya H, Utsumi T, Inoue K, Kato N, Sasaki T. Sensitivity to seasona changes in panic disorder patients. Psychiatry Clin Neurosci 2006; 60: 379-83.

22 Boschloo L, Spijker AT, Hoencamp E, Kupka R, Nolen WA, Schoevers RA, et al. Predictors of the onset of manic symptoms and a (hypo)manic episode in patients with major depressive disorder. PLOS One 2014; 9: e106871.

23 Levitt AJ, Boyle MH, Joffe RT, Baumal Z. Estimated prevalence of the seasonal subtype of major depression in a Canadian community sample. Can J Psychiatry 2000; 45: 650-4.

24 Allen JM, Lam RW, Remick RA, Sadovnick AD. Depressive symptoms and family history in seasonal and nonseasonal mood disorders. Am J Psychiatry 1993; 150 $443-8$

25 Michalak EE, Wilkinson C, Hood K, Dowrick C. Seasonal and nonseasonal depression: how do they differ? Symptom profile, clinical and family history in a genera population sample. J Affect Disord 2002; 69: 185-92.

26 Steinhausen $\mathrm{HC}$, Gundelfinger R, Winkler Metzke C. Prevalence of self-reported seasonal affective disorders and the validity of the seasonal pattern assessment questionnaire in young adults. Findings from a Swiss community study. J Affect Disord 2009; 115: 347-54

27 Akhter A, Fiedorowicz JG, Zhang T, Potash JB, Cavanaugh J, Solomon DA, et al. Seasonal variation of manic and depressive symptoms in bipolar disorder. Bipolar Disord 2013; 15: 377-84.

28 Friedman E, Gyulai L, Bhargava M, Landen M, Wisniewski S, Foris J, et al. Seasonal changes in clinical status in bipolar disorder: a prospective study in 1000 STEP-BD patients. Acta Psychiatr Scand 2006; 113: 510-17.

29 Bauer M, Glenn T, Grof P, Rasgon NL, Marsh W, Sagduyu K, et al. Relationship among latitude, climate, season and self-reported mood in bipolar disorder. J Affect Disord 2009; 116: 152-7.

30 Murray G, Lam RW, Beaulieu S, Sharma V, Cervantes P, Parikh SV, et al. Do symptoms of bipolar disorder exhibit seasonal variation? A multisite prospective investigation. Bipolar Disord 2011; 13: 687-95.

31 Geoffroy PA, Bellivier F, Scott J, Etain B. Seasonality and bipolar disorder: A systematic review, from admission rates to seasonality of symptoms. J Affect Disord 2014; 168C: 210-23.

32 Posternak MA, Zimmerman M. Lack of association between seasonality and psychopathology in psychiatric outpatients. Psychiatry Res 2002; 112: 187-94.

33 Sakamoto K, Nakadaira S, Kamo K, Kamo T, Takahashi K. A longitudinal follow-up study of seasonal affective disorder. Am J Psychiatry 1995; 152: 862-8.

34 Young MA, Watel LG, Lahmeyer HW, Eastman Cl. The temporal onset of individual symptoms in winter depression: differentiating underlying mechanisms. I Affect Disord 1991; 22: 191-7.

35 Lam RW, Tam EM, Yatham LN, Shiah IS, Zis AP. Seasonal depression: the dual vulnerability hypothesis revisited. J Affect Disord 2001; 63: 123-32.

36 Winthorst WH, Roest AM, Bos EH, Meesters Y, Penninx BW, Nolen WA, et al. Selfattributed seasonality of mood and behavior: a report from the Netherlands study of depression and anxiety. Depress Anxiety 2014; 31: 517-23.

37 Murray GW, Hay DA, Armstron SM. Personality factors in seasonal affective disorder: is seasonality an aspect of neuroticism? Person Individ Diff 1995; 19: 613-7.

38 Enns MW, Cox BJ, LevittAJ, Levitan RD, Morehouse R, Michalak EE, et al. Personality and seasonal affective disorder: results from the CAN-SAD study. J Affect Disord 2006; 93: 35-42.

39 Bagby RM, Schuller DR, Levitt AJ, Joffe RT, Harkness KL. Seasonal and nonseasonal depression and the five-factor model of personality. J Affect Disord 1996; 38: 89-95.

40 Rohan KJ, Roecklein KA, Lacy TJ, Vacek PM. Winter depression recurrence one year after cognitive-behavioral therapy, light therapy, or combination treatment. Behav Ther 2009; 40: 225-38. 